\title{
Teores de macronutrientes em folhas de goiabeira fertirrigada com nitrogênio
}

\author{
José Dantas Neto', José L. Maciel ${ }^{2}$, Aaron de S. Alves ${ }^{1}$, \\ Carlos A. V. de Azevedo ${ }^{1}$, Pedro D. Fernandes ${ }^{1}$ \& Vera L. A. de Lima ${ }^{1}$
}

\begin{abstract}
RESUMO
O objetivo deste estudo foi diagnosticar os teores de macronutrientes nitrogênio, fósforo, potássio, cálcio e magnésio nas folhas de goiabeira, em função de diferentes lâminas de irrigação (1144, 1465, 1785 e 2106 mm no primeiro ciclo, e 915, 1308, 1686 e $2093 \mathrm{~mm}$ no segundo ciclo produtivo) e níveis de fertilizantes nitrogenados $\left(50,100,150\right.$ e $\left.200 \mathrm{~kg} \mathrm{ha}^{-1}\right)$. Verificou-se efeito apenas isolado dos fatores lâminas de água e adubação nitrogenada sobre as concentrações dos macronutrientes estudados. A lâmina de água exerceu efeito linear positivo na concentração de fósforo e efeito quadrático na concentração de magnésio, nos dois ciclos produtivos, enquanto a adubação nitrogenada não influenciou os teores desses elementos. A concentração de potássio respondeu de forma quadrática à lâmina de água no primeiro ciclo produtivo e à adubação nitrogenada no segundo. A lâmina de água teve efeito linear positivo sobre o cálcio apenas no segundo ciclo; já o efeito da adubação nitrogenada foi quadrático e somente no primeiro ciclo. O efeito da adubação nitrogenada no teor de nitrogênio foi quadrático no primeiro ciclo produtivo e linear positivo no segundo; entretanto, a lâmina de água não exerceu efeito algum.
\end{abstract}

Palavras-chave: Psidium guajava L., fruticultura brasileira, nutrição de plantas, irrigação localizada

\section{Macronutrient contents in guava leaves fertigated with nitrogen}

\begin{abstract}
This study aimed to diagnose the contents of macronutrients nitrogen, phosphorus, potassium, calcium and magnesium in the leaves of guava, under different irrigation depths (1144, 1465, 1785 and 2106 $\mathrm{mm}$ in the first cycle, and 915, 1308, 1686 and $2093 \mathrm{~mm}$ in the second productive cycle) and levels of nitrogen fertilizer (50, 100, 150 and $200 \mathrm{~kg} \mathrm{ha}^{-1}$ ). Only isolated effects of the factors (water depths and nitrogen fertilization) were verified on the concentrations of the studied micronutrients. The water depth exercised positive linear effect on the phosphorus concentration and quadratic effect on the concentration of magnesium in both productive cycles, while the nitrogen fertilization did not influence the contents of these elements. The potassium concentration showed the quadratic effect of the water depth in the first cycle and of the nitrogen fertilization in the second one. The water depth had a positive linear effect on calcium just in the second cycle, whereas the effect of the nitrogen fertilization was quadratic only in the first cycle. The effect of the nitrogen fertilization on the concentration of nitrogen was quadratic in the first cycle and positive linear in the second one; however, the water depth did not exercise any effect.
\end{abstract}

Key words: Psidium guajava L., brazilian horticulture, nutrition of plants, localized irrigation 


\section{INTRODUÇÃO}

No Nordeste brasileiro, a fruticultura apoia-se em condições climáticas singulares, combinando as constâncias de calor e insolação com a baixa umidade relativa do ar registrada no semiárido. Nessas condições, a área cultivada e o volume de frutas produzidas na região se expandiram de forma significativa apresentando rendimentos e qualidade de produtos superiores aos das demais regiões do Brasil (Lima \& Miranda, 2001). Tornando-se, assim, a principal região produtora do País (Santos et al., 2009).

A cultura da goiabeira (Psidium guajava L.) se destaca em meio às diversas espécies frutíferas cultivadas nesta região, tanto para consumo in natura como para industrialização (Dantas et al., 2007). Constituindo-se em um segmento de grande importância socioeconômico (Moura \& Moura, 2011). Com ótimas possibilidades de negócios com polpas e com frutos ao natural (Pereira \& Nachtigal, 2002).

Ainda que extremamente importante para o Nordeste e para o País, pouco se conhece sobre a fisiologia, nutrição mineral, irrigação e fertirrigação da cultura (Dantas et al., 2007). Havendo, portanto, a necessidade de se realizar pesquisas que efetivamente definam as melhores tecnologias, para incrementar a produtividade e a qualidade dos frutos produzidos, tornandoos mais competitivo nos mercados nacional e internacional (Oliveira et al., 2008).

Neste contexto, embora a irrigação e a adubação sejam condições essenciais para esta implementação (Teixeira et al., 2011). As quantidades de água e nutrientes aplicadas, nem sempre atendem as necessidades hídricas e nutricionais da cultura. Agravando-se ainda mais com o desconhecimento da fertilidade do solo e, principalmente, da exigência nutricional da planta, permitindo a adoção de manejos inadequados que afetam não só o crescimento, mas também o seu rendimento (Sousa et al., 2010). Constituindo-se, assim, em um dos maiores desafios para pesquisadores em fertilidade do solo e nutrição de plantas, principalmente onde ocorrem limitações na produtividade das culturas (Carvalho et al., 2002).

Mendonça et al., (1999) destacarem que no caso de nutrientes muito móveis, como o nitrogênio, a fertirrigação possibilita maior divisão da sua aplicação, reduzindo as perdas por lixiviação; apesar disto, deve-se ter especial atenção quanto ao uso desse nutriente visando aumentar a eficiência de sua utilização, quantificando níveis adequados e conhecendo a magnitude e a velocidade das suas transformações (Alves et al., 2010). Permitindo, assim, a adequação dos programas de adubação a tempo de não comprometer a produção do pomar (Danilo et al., 2009). Aumentando, então, a eficiência do uso dos fertilizantes oferecendo, à planta, o nutriente prontamente disponível na solução do solo para ser absorvido (Oliveira et al., 2008). Deste modo, conhecer os fatores limitantes à produção de goiabas permite a adoção de programas de adubação mais adequados, com resultados favoráveis ao aumento da produtividade e, consequentemente, do lucro do fruticultor (Danilo et al., 2009).

Deste modo, considerando a importância da cultura para o atual cenário econômico nacional e o caráter pioneiro desta iniciativa no âmbito regional, o trabalho tem como objetivo diagnosticar os teores de macro nutrientes nas folhas de goiabeira (Psidium guajava L.) cv. Paluma, em função de diferentes lâminas de irrigação e níveis de fertilizantes nitrogenados.

\section{Material e Métodos}

O experimento foi conduzido em campo, em um pomar de goiabeira cv. Paluma, com quatro anos de idade, instalado no espaçamento de 6,0 x 5,0 m na Fazenda Experimental da Empresa Estadual de Pesquisa Agropecuária da Paraíba EMEPA, no município de Itaporanga, $\mathrm{PB}$, localizado sob as seguintes coordenadas geográficas: $07^{\circ} 18^{\prime} 00^{\prime}$ "de latitude Sul e $38^{\circ} 09^{\prime} 00^{\prime \prime}$ de longitude Oeste. A altitude média local é de $291 \mathrm{~m}$. O clima da região, segundo a classificação de Köppen, é do tipo $\mathrm{AW}^{\prime}$ - quente e úmido com chuvas de verão e outono, com pluviosidade em torno de $806 \mathrm{~mm}$ anuais, distribuídas em duas estações, uma chuvosa, de janeiro a abril, com mais de $80 \%$ das precipitações e outra seca, com chuvas espaçadas nos demais meses do ano. A região possui ainda temperatura média anual da ordem de $24^{\circ} \mathrm{C}$ e umidade relativa do ar de $73,8 \%$. As precipitações pluviométricas incidentes na região durante a condução dos experimentos estão apresentadas na Figura 1.

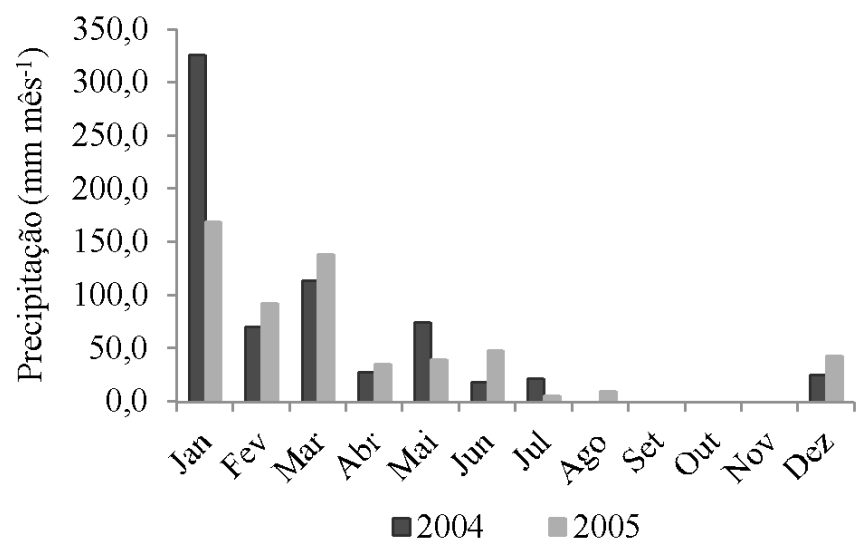

Figura 1. Precipitação pluviométrica ocorrida na região durante o período experimental

O solo do local foi classificado originalmente, como Neossolo (Embrapa, 1999), de textura franco-argilosa e relevo tipicamente plano, do qual, retirou-se uma amostra composta, formada por diversas amostras simples coletadas na projeção da copa das plantas úteis em duas profundidades: $0-20 \mathrm{~cm} \mathrm{e}$ $20-40 \mathrm{~cm}$. Feito isto, as amostras foram acondicionadas em sacos plásticos, devidamente identificadas e encaminhadas para caracterização física e química, no Laboratório de Irrigação e Salinidade (LIS) da Universidade Federal de Campina Grande (UFCG), cujos resultados são apresentados nas Tabelas 1 e 2, respectivamente.

Com base nestes resultados e conforme sugestão de adubação para a cultura da goiabeira foi realizada, após a poda de frutificação, a aplicação em cobertura de $60 \mathrm{~kg} \mathrm{ha}^{-1} \mathrm{de}_{2} \mathrm{O}_{5}$ na forma de superfosfato simples e $90 \mathrm{~kg} \mathrm{ha}^{-1} \mathrm{de} \mathrm{K}_{2} \mathrm{O}$ na forma de nitrato de potássio, o qual teve o valor, correspondente ao nitrogênio contido em sua composição complementado 
Tabela 1. Caracterização física do solo cultivado com goiabeira (Psidium guajava L.) cultivar Paluma

\begin{tabular}{lccc}
\hline \multirow{2}{*}{ Características } & \multirow{2}{*}{ Unidades } & \multicolumn{2}{c}{ Profundidades (cm) } \\
\cline { 3 - 4 } Areia & $\mathrm{g} \mathrm{kg}^{-1}$ & $\mathbf{0 - 2 0}$ & $\mathbf{2 0 - 4 0}$ \\
Silte & $\mathrm{g} \mathrm{kg}^{-1}$ & 269,2 & 446,1 \\
Argila & $\mathrm{g} \mathrm{kg}^{-1}$ & 311,9 & 281,5 \\
Classificação textural & - & Franco-argilosa & Franco-argilosa \\
Densidade do solo & $\mathrm{kg} \mathrm{dm}^{-3}$ & 1,29 & 1,27 \\
Densidade das partículas & $\mathrm{kg} \mathrm{dm}^{-3}$ & 2,77 & 2,76 \\
Porosidade total & $\%$ & 53,42 & 53,98 \\
\hline
\end{tabular}

com ureia, sendo as quantidades calculadas conforme cada tratamento.

Os estudos foram conduzidos no delineamento experimental em blocos casualizados, em esquema fatorial $4 \times 4$, compondo 16 tratamentos, com quatro repetições cada um, constituídos por quatro lâminas de irrigação correspondentes a 60, 100, 140 e $180 \%$ da ETc, estabelecida com base na evapotranspiração de referência (ETo) diária estimada por meio do tanque classe A e coeficiente da cultura $(\mathrm{kc})$ para cada fase fonológica da cultura da goiabeira (Bassoi et al., 2001); desta forma, as lâminas de irrigação aplicadas à cultura conforme cada tratamento foram 491,$2 ; 811,8 ; 1132,4$ e $1453,1 \mathrm{~mm}$ no primeiro ciclo e 579,6 ; 972,$1 ; 1350,5$ e $1757,0 \mathrm{~mm}$ no segundo ciclo produtivo, combinadas com quatro níveis de nitrogênio aplicados nas formas de nitrato de potássio e ureia nas quantidades de 50,100, 150 e $200 \mathrm{~kg} \mathrm{ha}^{-1}$, sendo as aplicações realizadas três vezes por semana via fertirrigação em ambos os ciclos produtivo. Para tal, utilizou-se injetor de fertilizantes do tipo Venturi, com descarga de $900 \mathrm{~mL} \mathrm{~min}^{-1}$.

Durante a condução do experimento as precipitações pluviométricas registradas na região, ao final de cada ciclo produtivo, foram de $652,8 \mathrm{~mm}$ no primeiro e $335,8 \mathrm{~mm}$ no segundo (Figura 1). Logo as lâminas totais de irrigação aplicadas (irrigação + precipitação) foram 1144; 1465; 1785 e $2106 \mathrm{~mm}$, no primeiro e 915; 1308; 1686 e $2093 \mathrm{~mm}$ no segundo ciclo produtivo.

As irrigações foram realizadas diariamente nos dois ciclos produtivos da cultura da goiabeira, sendo o primeiro compreendido entre os meses de janeiro a agosto de 2004 e o segundo de setembro de 2004 a março de 2005, por um sistema de irrigação localizada, do tipo microaspersão, acionado por um conjunto motobomba elétrico, trifásico, do tipo KSB, com três cv de potência, rotação de $3450 \mathrm{rpm}$ e vazão de 15 $\mathrm{m}^{3} \mathrm{~h}^{-1}$, tubulação principal de PVC e linha de acesso a cada parcela experimental composta por mangueiras de polietileno flexível com $16 \mathrm{~mm}$ de diâmetro contendo microaspersores autocompensantes com vazão nominal de $50 \mathrm{~L} \mathrm{~h}^{-1}$, funcionando à pressão de $250 \mathrm{kPa}$, proporcionando um raio molhado de 2,5 $\mathrm{m}$, com um microaspersor em cada planta, formando uma faixa molhada ao longo da linha de cultivo.
Para diagnosticar os teores de nutrientes nas folhas de goiabeira, coletou-se 25 amostras foliares, em cada parcela experimental, aos 190 dias após a poda de produção de cada ciclo. As amostras foram acondicionadas em sacos de papel e postas para secar em estufa com circulação forçada a uma temperatura de $60{ }^{\circ} \mathrm{C}$. Decorrido tempo suficiente para secagem, as folhas foram trituradas em moinho, postas em recipientes hermeticamente fechados, devidamente identificadas e encaminhadas para posterior análise, onde, o teor de $\mathrm{N}$ foi determinado por digestão sulfúrica, enquanto que a determinação dos demais nutrientes: $\mathrm{P}, \mathrm{K}, \mathrm{Ca}$ e $\mathrm{Mg}$ foi realizada por digestão nítrico-perclórica conforme Malavolta et al. (1997).

Os resultados foram submetidos a análise de variância e regressão, avaliando os efeitos isolados de cada fator, assim como a interação entre eles, à significância de 0,01 e 0,05 de probabilidade; para tanto, foi utilizado o pacote estatístico SISVAR.

\section{Resultados E Discussão}

Por meio dos resultados apresentados na Tabela 3 observase que os teores dos macronutrientes: nitrogênio $(\mathrm{N})$, fósforo $(\mathrm{P})$, potássio $(\mathrm{K})$, cálcio $(\mathrm{Ca})$ e magnésio $(\mathrm{Mg})$ encontrados nas folhas de goiabeira Paluma, foram significativamente influenciados pelas diferentes lâminas de irrigação e níveis de nitrogênio aplicados à cultura, ocorrendo efeitos isolados a nível de 0,01 e 0,05 de probabilidade.

Com base nestes resultados nota-se que para o primeiro ciclo houve resposta linear em nível de 0,01 de probabilidade do fator lâmina total de irrigação sobre os teores de $\mathrm{P}$ e $\mathrm{Mg}$, e efeito quadrático em nível de 0,05 de probabilidade para os teores de $\mathrm{K}$ presentes nas folhas de goiabeira. No segundo ciclo produtivo, ocorreram efeito linear em nível de 0,01 de probabilidade sobre o conteúdo de fósforo $\mathrm{P}$, Ca e quadrático sobre o teor de $\mathrm{Mg}$ nas folhas, sem significância para as demais variáveis.

Assim como às lâminas de irrigação, os níveis de nitrogênio testados neste estudo influenciaram sensivelmente os teores de nutrientes em folhas de P. guajava cv. Paluma, em ambos os ciclos de produção tendo-se observado, no primeiro, efeito linear e quadrático a nível de 0,01 e 0,05 de probabilidade aos teores de $\mathrm{N}$ e $\mathrm{Ca}$ encontrados nas folhas de goiabeira e no segundo, houve efeito significativo a nível de 0,01 de probabilidade dos níveis de adubação nitrogenada testados sobre os teores de $\mathrm{N}$ e $\mathrm{K}$.

No primeiro ciclo produtivo verificaram-se teores foliares de macronutrientes superiores ao observados no segundo ciclo produtivo (Tabela 3). Segundo Natale et al. (1996), as faixas e teores adequados de macronutrientes em folhas de goiabeira para a cultivar Paluma são as seguintes: N (20-23 $\left.\mathrm{g} \mathrm{kg}^{-1}\right)$; P $\left(1,4-1,8 \mathrm{~g} \mathrm{~kg}^{-1}\right) ; \mathrm{K}\left(14-17 \mathrm{~g} \mathrm{~kg}^{-1}\right) ; \mathrm{Ca}\left(7-11 \mathrm{~g} \mathrm{~kg}^{-1}\right)$; e $\mathrm{Mg}(3,4-4$ $\left.\mathrm{g} \mathrm{kg}^{-1}\right)$; desta forma, no segundo ciclo todos os macronutrientes

Tabela 2. Caracterização química do solo cultivado com goiabeira (Psidium guajava L.) cultivar Paluma

\begin{tabular}{|c|c|c|c|c|c|c|c|c|c|c|c|}
\hline \multirow{2}{*}{$\begin{array}{l}\text { Profundidades } \\
\text { (cm) }\end{array}$} & \multirow{2}{*}{$\begin{array}{c}\mathrm{pH} \\
\mathrm{H}_{2} \mathrm{O}\end{array}$} & \multirow{2}{*}{$\begin{array}{l}\mathrm{MO}^{1} \\
\mathrm{~g} \mathrm{~kg}^{-1}\end{array}$} & $P$ & K & $\mathrm{Ca}$ & $\mathrm{Mg}$ & $\mathrm{H}^{+}+\mathrm{Al}^{3+}$ & $\mathrm{Na}$ & $\overline{T^{2}}$ & \multirow{2}{*}{$\begin{array}{c}\mathrm{S} \\
\mathrm{mg} \mathrm{dm}^{-3}\end{array}$} & \multirow{2}{*}{$\begin{array}{c}C E^{3} \\
d S m^{-1}\end{array}$} \\
\hline & & & \multicolumn{2}{|c|}{$\mathrm{mg} \mathrm{dm}^{-3}$} & & & $\mathrm{cmol}_{\mathrm{c}} \mathrm{dm}^{2}$ & & & & \\
\hline $0-20$ & 8,07 & 1,03 & 14,55 & 148,58 & 6,8 & 7,68 & 0,0 & 1,87 & 16,73 & 16,73 & 0,30 \\
\hline $20-40$ & 7,40 & 0,65 & 11,37 & 125,12 & 7,2 & 7,88 & 0,0 & 2,05 & 17,45 & 17,45 & 0,33 \\
\hline
\end{tabular}

${ }^{1}$ Matéria orgânica; ${ }^{2}$ Capacidade de troca catiônica; ${ }^{3}$ Condutividade elétrica 
Tabela 3. Resumo da análise de variância e regressão para os teores de nitrogênio $(\mathrm{N})$, fósforo (P), potássio (K), cálcio (Ca) e magnésio (Mg) em $\mathrm{g} \mathrm{kg}^{-1}$, em folhas de goiabeira cv. Paluma no primeiro e no segundo ciclos de produção

\begin{tabular}{|c|c|c|c|c|c|c|c|c|c|c|c|}
\hline \multirow[b]{2}{*}{ Fonte de variação } & \multirow[b]{2}{*}{ GL } & \multicolumn{10}{|c|}{ Quadrado médio } \\
\hline & & \multicolumn{5}{|c|}{ Primeiro ciclo produtivo } & \multicolumn{5}{|c|}{ Segundo ciclo produtivo } \\
\hline Lâminas (L) & 3 & $3,24^{\text {ns }}$ & $0,68^{* *}$ & $3,23^{*}$ & $0,08^{\text {ns }}$ & $0,53^{* *}$ & $8,144^{\text {ns }}$ & $0,84^{* *}$ & $0,59^{\text {ns }}$ & $35,37^{\star *}$ & $0,623^{\star \star}$ \\
\hline Regressão quadrática & 1 & $4,98^{\text {ns }}$ & $0,01^{\text {ns }}$ & $5,70^{\star}$ & $0,12^{\text {ns }}$ & $0,59^{\star}$ & $4,75^{\text {ns }}$ & $0,003^{\text {ns }}$ & $0,86^{\text {ns }}$ & $7,03^{\text {ns }}$ & $0,56^{\star *}$ \\
\hline Regressão cúbica & 1 & $2,79^{\text {ns }}$ & $0,001^{\mathrm{ns}}$ & $0,40^{\text {ns }}$ & $0,02^{\text {ns }}$ & $0,43^{\text {ns }}$ & $3,21^{\text {ns }}$ & $0,083^{\text {ns }}$ & $0,0001^{\mathrm{ns}}$ & $0,0001^{\mathrm{ns}}$ & $0,0001^{\text {ns }}$ \\
\hline Níveis de nitrogênio (N) & 3 & $47,69^{\star \star}$ & $0,06^{\text {ns }}$ & $0,51^{\text {ns }}$ & $8,10^{*}$ & $0,19^{\text {ns }}$ & $149,64^{\star \star}$ & $0,069^{\text {ns }}$ & $4,09^{\star \star}$ & $5,51^{\text {ns }}$ & $0,07^{\text {ns }}$ \\
\hline Regressão cúbica & 1 & $0,87^{\text {ns }}$ & $0,01^{\text {ns }}$ & $0,43^{\text {ns }}$ & $0,15^{\text {ns }}$ & $0,0001^{\text {ns }}$ & $3,25^{\text {ns }}$ & $0,0006^{\text {ns }}$ & $0,0001^{\text {ns }}$ & $0,0001^{\mathrm{ns}}$ & $0,0001^{\text {ns }}$ \\
\hline$L \times N$ & 9 & $2,95^{\text {ns }}$ & $0,007^{\mathrm{ns}}$ & $0,62^{\text {ns }}$ & $0,29^{\text {ns }}$ & $0,17^{\text {ns }}$ & $1,46^{\text {ns }}$ & $0,032^{\mathrm{ns}}$ & $1,09^{\text {ns }}$ & $1,20^{\text {ns }}$ & $0,02^{\text {ns }}$ \\
\hline Bloco & 3 & $0,54^{\text {ns }}$ & $0,009^{\text {ns }}$ & $0,79^{\text {ns }}$ & 3,89 & $0,03^{\text {ns }}$ & $12,54^{\mathrm{ns}}$ & $0,006^{\text {ns }}$ & $2,84^{\text {ns }}$ & 0,74 & $0,05^{\text {ns }}$ \\
\hline Resíduo & 45 & 2,17 & 0,039 & 0,91 & 2,39 & 0,09 & 6,59 & 0,033 & 1,24 & 1,88 & 0,07 \\
\hline CV (\%) & & 6,87 & 12,16 & 7,28 & 10,10 & 9,58 & 13,08 & 15,53 & 8,30 & 12,31 & 11,80 \\
\hline Média geral $\left(\mathrm{g} \mathrm{kg}^{-1}\right)$ & & 21,46 & 1,63 & 13,44 & 15,33 & 3,14 & 19,12 & 1,17 & 13,34 & 11,15 & 2,31 \\
\hline
\end{tabular}

analisados estão fora da faixa considerada adequada para a cultura da goiabeira, enquanto que no primeiro apenas o $\mathrm{Mg}$ está fora da faixa adequada. Considerando que se aplicou a mesma quantidade de adubos nas plantas, essa diminuição deve ter ocorrido por lixiviação de nutrientes provocada por
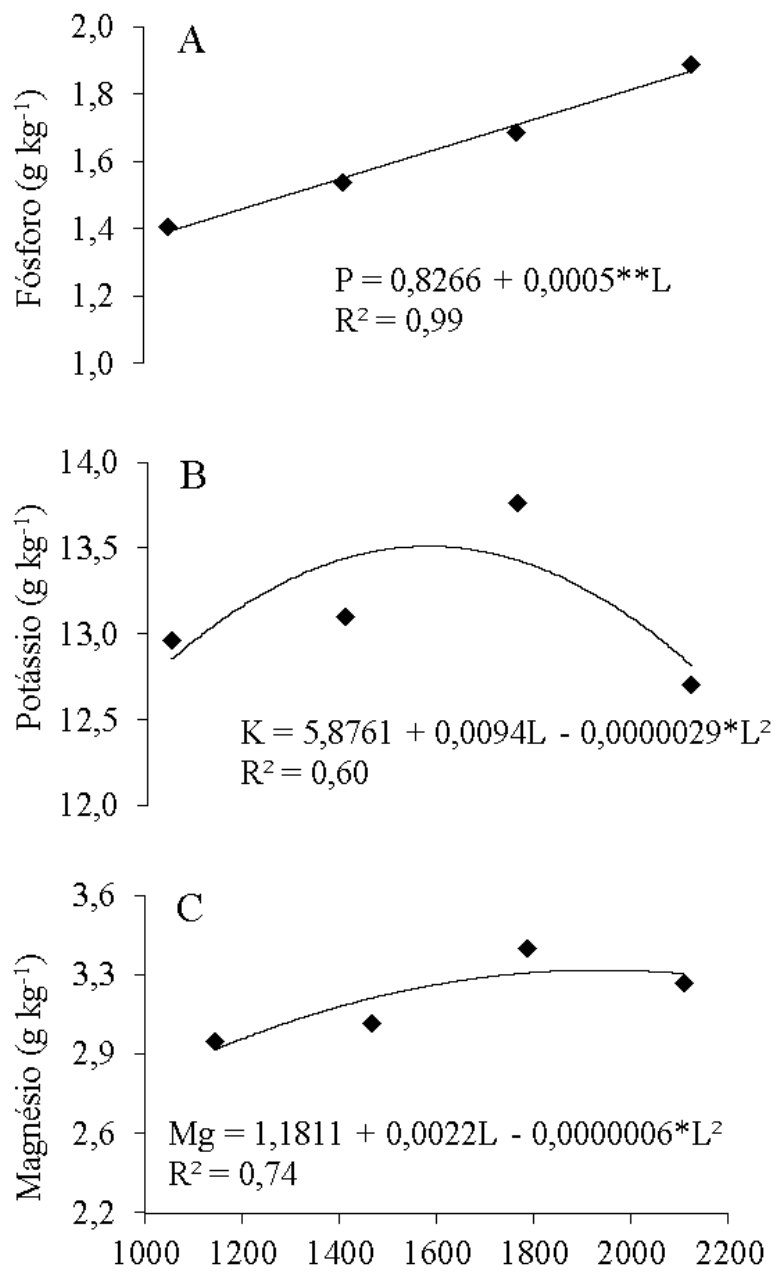

Lâmina total (irrigação + precipitação) $(\mathrm{mm})$ ocorrências de fortes chuvas ao final do segundo ciclo (Figura 1), entretanto, não foram observados, no campo, sintomas de deficiências destes elementos.

Em meio aos resultados significativos obtidos na Tabela 3, observa-se na Figura 2 as tendências e comportamentos dos
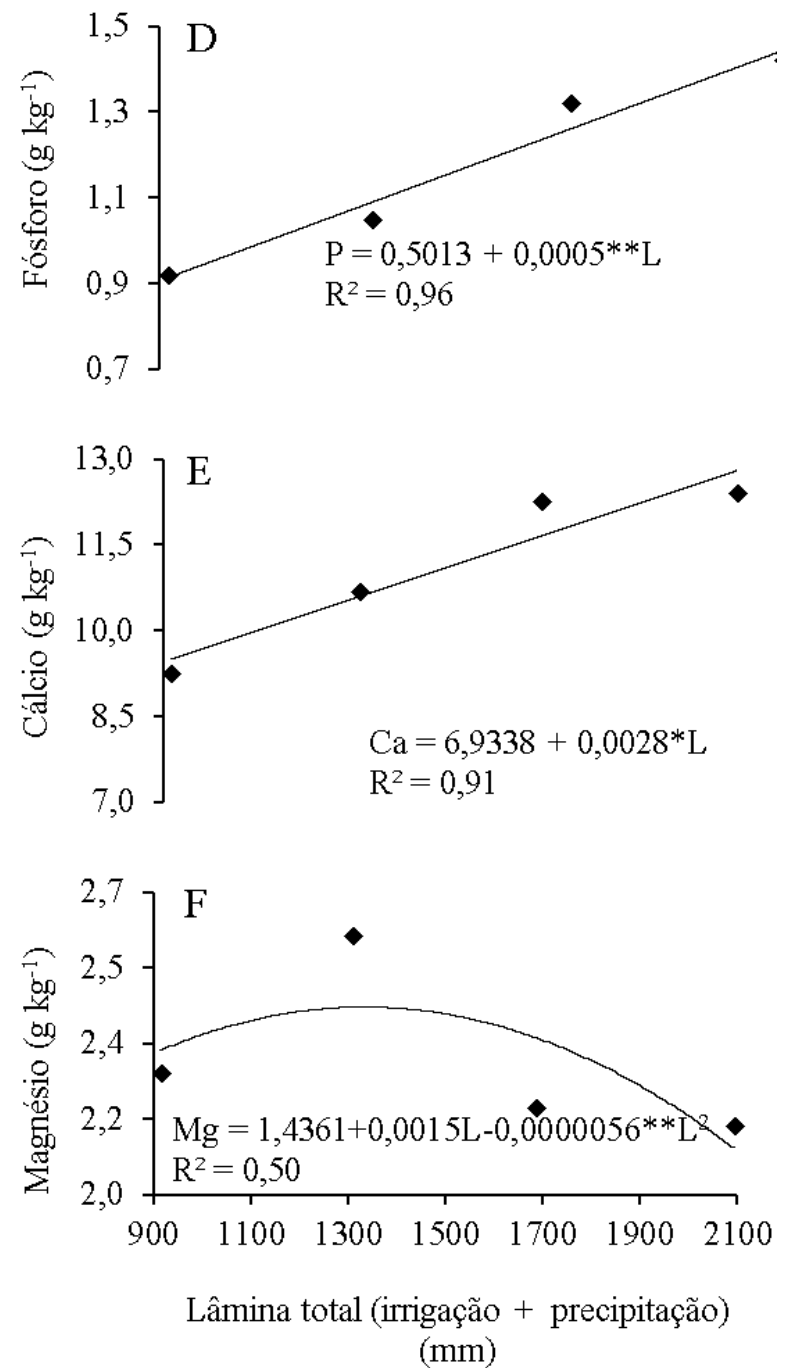

Figura 2. Teores de fósforo, potássio, magnésio e cálcio nas folhas de goiabeira Paluma em função das lâminas de irrigação (A, B, C no primeiro ciclo produtivo; $D, E, F$ no segundo ciclo produtivo) 
teores de $\mathrm{P}, \mathrm{K}, \mathrm{Ca}$ e Mg nas folhas de goiabeira cv. Paluma, obtidos em função das diferentes lâminas de irrigação testadas, respectivamente nos primeiro e segundo ciclos de produção.

Tanto no primeiro como no segundo ciclo produtivo da cultura verifica-se o aumento linear dos teores de P nas folhas de goiabeira com o acréscimo da lâmina de irrigação (Figura 2A e 2D). O teor de cálcio também aumentou de forma linear com o aumento da lamina de irrigação (Figura 2E). A cada 100 $\mathrm{mm}$ de água acrescentado ao solo houve um aumento de $0,05 \mathrm{~g}$ $\mathrm{kg}^{-1}$ de $\mathrm{P}$ e 0,28 de $\mathrm{Ca} \mathrm{g} \mathrm{kg}^{-1}$ nas folhas de goiabeira.

Desse modo, infere-se que o aumento da disponibilidade de água no solo pode ter promovido o aumento dos teores destes nutrientes na faixa de solo explorada pelo sistema radicular da cultura, otimizando a absorção e translocação até as folhas. Uma vez que, segundo Almeida et al. (2002), a absorção de nutrientes pelas plantas está diretamente relacionada à disponibilidade destes e da água no solo. Assim um incremento na aplicação de água para uma mesma adubação pode levar a maior absorção de nutrientes pelas plantas, resultando em maiores teores de nutrientes nestas.

O modelo matemático que melhor representou os teores de $\mathrm{K}$ e $\mathrm{Mg}$ encontrados nas folhas de goiabeira foi o quadrático (Figuras 2B, 2C e 2F). A concentração máxima de K encontrada $13,5 \mathrm{~g} \mathrm{~kg}^{-1}$ foi obtida com uma lamina de $1621 \mathrm{~mm}$, enquanto que para o $\mathrm{Mg}$ as concentrações máximas encontradas destes nutriente nas folhas foram, respectivamente de $3,2 \mathrm{~g} \mathrm{~kg}^{-1} \mathrm{e}$ 2,44 $\mathrm{g} \mathrm{kg}^{-1}$ com a aplicações de 1864 e $1339 \mathrm{~mm}$, no primeiro e segundo ciclo produtivo (Figura $2 \mathrm{C}$ e $2 \mathrm{~F}$ ).

Os baixos teores de potássio encontrados com a aplicação da menor e da maior lâmina total de água aplicada mostram
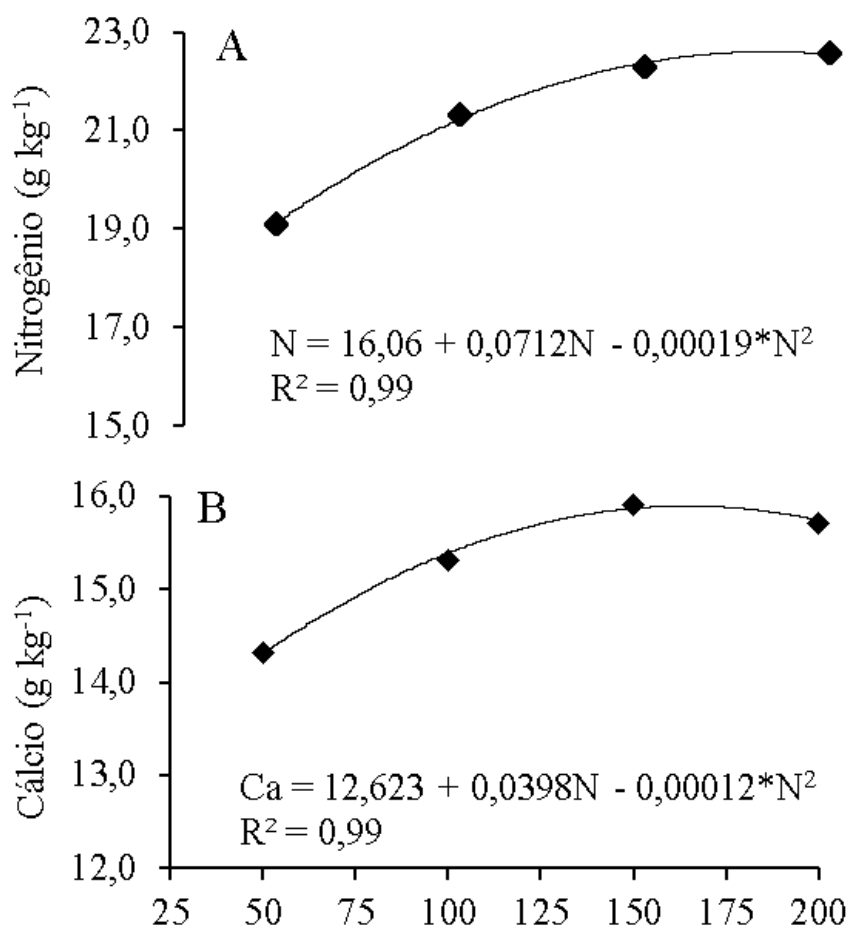

Níveis de nitrogênio $\left(\mathrm{kg} \mathrm{ha}^{-1}\right)$ que tanto o déficit quanto o excesso de água no solo proporcionam reduções consideráveis nas quantidades deste nutriente nas folhas da cultura. Neste sentido, Teixeira et al. (2011) ressaltam que a sua disponibilidade é determinada pelas condições de difusão e de fluxo de massa no solo que, por sua vez, são funções do seu conteúdo de água. Onde a lixiviação ocorre em função do teor desse nutriente na solução do solo e da quantidade de água que percola através do solo (Vilela et al., 2004). O que pode ter contribuído para a redução da disponibilidade de K próximo a zona de absorção da cultura, em resposta às maiores lâminas de irrigação aplicadas (2106 e $2093 \mathrm{~mm}$, no primeiro e segundo ciclo, respectivamente). Em contrapartida, Sousa et al. (2001) ressaltam que o manejo adequado da irrigação manterá o solo em estado ótimo de umidade favorecendo a disponibilidade e a absorção de potássio pela cultura.

Para Rozane et al. (2009) quando acompanhada da irrigação uma adubação adequada favorece o desenvolvimento dessa frutífera e, por sua vez, o florescimento, possibilitando a colheita de frutos nas épocas desejadas pelo produtor. Apesar disto, Taiz \& Zeiger (2004), enfatizam que o excesso de água no solo em nível superior à capacidade de campo, causa distúrbios de hipoxia e anoxia afetando a respiração das células do sistema radicular.

Tal como as lâminas de irrigação, os níveis de nitrogênio testados neste estudo, influenciaram sobremaneira os teores de nutrientes nas folhas de goiabeira cv. Paluma, constatandose efeito isolado deste fator sobre os conteúdos de $\mathrm{N}$ e $\mathrm{Ca}$ no primeiro ciclo (Figuras 3A e B) e N e K no segundo ciclo produtivo (Figuras $3 \mathrm{C}$ e D).
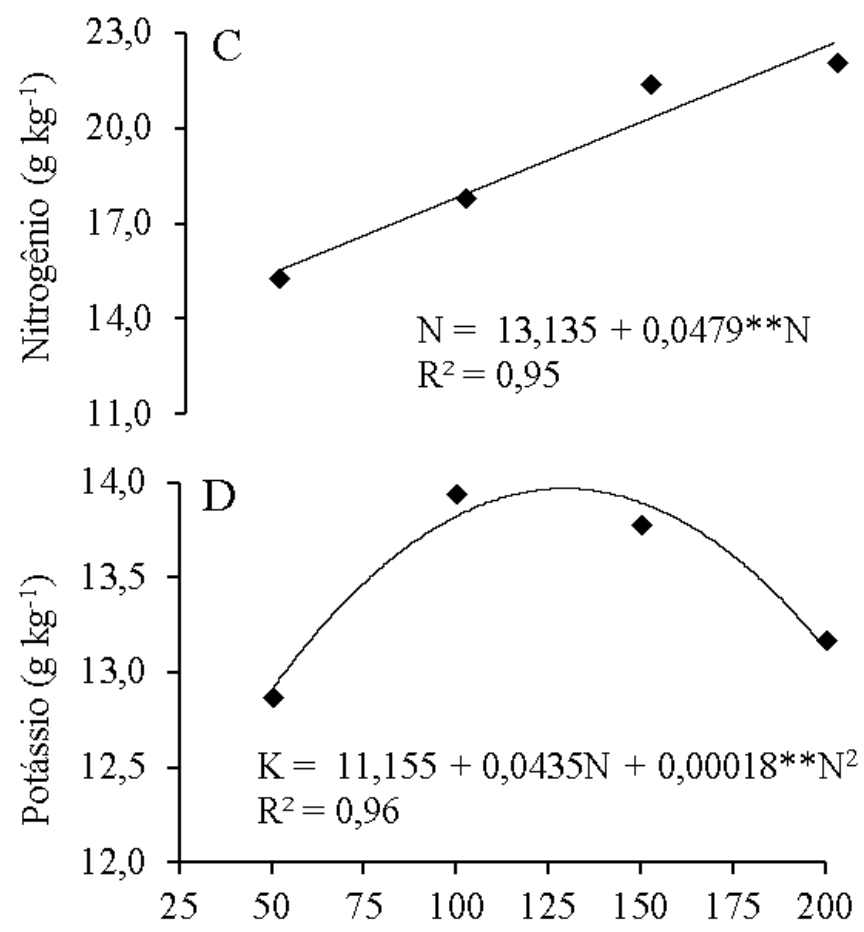

Níveis de nitrogênio $\left(\mathrm{kg} \mathrm{ha}^{-1}\right)$

Figura 3. Teores de nitrogênio, cálcio e potássio nas folhas de goiabeira Paluma em função dos níveis de nitrogênio. (A e B no primeiro ciclo produtivo; C e D no segundo ciclo produtivo) 
$\mathrm{O}$ teor de $\mathrm{N}$ nas folhas de goiabeira respondeu de forma quadrática, no primeiro ciclo (Figura 3A), e de forma linear no segundo ciclo produtivo (Figura $3 \mathrm{C}$ ) à quantidade de adubação nitrogenada aplicada. A maior concentração de $\mathrm{N}$ nas folhas, $22,7 \mathrm{~g} \mathrm{~kg}^{-1}$, foi obtida quando se aplicou uma dose de $187 \mathrm{~kg}$ de $\mathrm{N} \mathrm{ha}^{-1}$, via fertirrigação. No segundo ciclo houve um incremento de $2,4 \mathrm{~g} \mathrm{~kg}^{-1}$ de $\mathrm{N}$ nas folhas de P. guajava cv. Paluma para cada $50 \mathrm{~kg}$ de $\mathrm{N} \mathrm{ha}^{-1}$ adicionado à fertirrigação, tendo em vista que o maior nível de $\mathrm{N}$ aplicado (200 $\mathrm{kg} \mathrm{ha}^{-1}$ ) proporcionou um acumulo de 22,72 $\mathrm{g} \mathrm{kg}^{-1}$ de $\mathrm{N}$ nas folhas de goiabeira.

De modo geral, no segundo ciclo produtivo a concentração de $\mathrm{N}$ encontrados nas folhas de goiabeira foi menor do que no primeiro. Tal fato pode ser explicado pela perda de $\mathrm{N}$ em função das maiores precipitações pluviométrica registradas ao final do segundo ciclo. Sant'Ana et al. (2010) ressalvam que o N é um elemento que se perde facilmente por lixiviação, volatilização e desnitrificação, no sistema solo-planta, e o manejo adequado da adubação nitrogenada é tido como um dos mais difíceis.

Em pesquisa realizada por Maia et al. (2007) observou-se em goiabeiras cv. Paluma no Vale do São Francisco teores foliares de $\mathrm{N}$ entre 20 e $25 \mathrm{mg} \mathrm{kg}^{-1}$ desde a brotação até o início de maturação dos frutos. Franco et al. (2007) verificaram para mudas de goiabeira da cv. Paluma o acúmulo total de $552 \mathrm{mg}$ de $\mathrm{N}$ planta $^{-1}$. Devido à grande suscetibilidade às condições ambientais e ao papel que desempenha, o nitrogênio é um elemento que apresenta as maiores dificuldades de manejo (Alves et al., 2010).

As concentrações de $\mathrm{Ca}$ e $\mathrm{K}$ nas folhas de goiabeira responderam de forma quadrática, à quantidade de adubação nitrogenada aplicada (Figuras 3B e D). Quanto ao acumulo de $\mathrm{Ca}$ nas folhas em resposta às fertirrigações nitrogenadas (Figura 3B) observa-se que a aplicação de $166 \mathrm{~kg}$ de $\mathrm{N} \mathrm{ha}^{-1}$ proporcionou maior concentração de Ca nas folhas de goiabeira $\left(15,9 \mathrm{~g} \mathrm{~kg}^{-1}\right)$, representando um acréscimo de $11,2 \%$ deste nutriente nas folhas em relação ao menor nível de $\mathrm{N}$ aplicado $\left(50 \mathrm{~kg} \mathrm{ha}^{-1}\right)$.

O teor de Ca obtido neste estudo (15,9 $\left.\mathrm{g} \mathrm{kg}^{-1}\right)$ foi superior ao encontrado por Prado \& Natale (2004) em goiabeiras no terceiro ano de cultivo (13 $\left.\mathrm{g} \mathrm{kg}^{-1}\right)$. Conforme Gomes et al. (2008) este valor encontra-se acima daqueles considerados adequados para a cultura da goiabeira (7 a $\left.15 \mathrm{~g} \mathrm{~kg}^{-1}\right)$.

Para o teor de K nas folhas (Figura 3D) observa-se que a

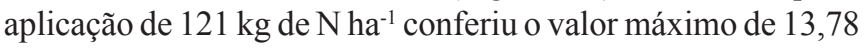
$\mathrm{g} \mathrm{kg}^{-1}$ no nível máximo do modelo estatístico, o qual promoveu um ganho de $6,99 \%$ quando comparado com o valor de 12,88 $\mathrm{g} \mathrm{kg}^{-1}$ obtido com a aplicação de $50 \mathrm{~kg}^{\mathrm{de}} \mathrm{N} \mathrm{ha}^{-1}$.

A redução dos teores foliares de $\mathrm{K}$, com a elevação do $\mathrm{N}$, no segundo ciclo produtivo, provavelmente se deu devido à competição no solo entre os íons $\mathrm{K}$ e $\mathrm{N}$ fornecido via fertirrigação. Ao se aumentar os níveis de fertirrigação com N, naturalmente ocorre incremento dos íons $\mathrm{NH}_{4}^{+}$, uma das formas preferenciais de absorção deste nutriente (Taiz \& Zeiger, 2004).

Assim, o aumento da eficiência de fertilizante tem sido cada vez mais almejado nas boas práticas de manejo da adubação de culturas, não buscando apenas reduzir custos de produção, mas também os possíveis impactos ambientais (Teixeira et al., 2011). Damatto Júnior et al. (2011) enfatizam que a diagnose foliar é atualmente recomendada para aprimorar os ajustes no programa de adubação e, sobretudo para avaliar a necessidade de aplicação de micronutrientes. Contribuindo para a melhoria das recomendações de adubação (Hoffmann et al., 2010). E fornecimento equilibrado dos nutrientes para obtenção de produções econômicas (Melo et al., 2010). Portanto, se utilizada corretamente, esta técnica contribuirá para o aumento da produtividade das culturas reduzindo as perdas de nutrientes por lixiviação e aumentando a eficiência do uso dos fertilizantes, visto que, oferece à planta o nutriente prontamente disponível na solução do solo para ser absorvido (Oliveira et al., 2008).

\section{Conclusões}

1. Verificaram-se efeitos isolados dos fatores lâmina de água e níveis de adubação nitrogenada. A lâmina de água exerceu efeito linear positivo na concentração de fósforo e efeito quadrático na concentração de magnésio, nos dois ciclos produtivos, enquanto que a adubação nitrogenada não influenciou os teores destes elementos.

2. A concentração de potássio respondeu de forma quadrática à lâmina de água no primeiro ciclo produtivo e à adubação nitrogenada no segundo.

3. A lâmina de água teve efeito linear positivo na concentração de cálcio apenas no segundo ciclo produtivo, já o efeito da adubação nitrogenada foi quadrático e somente no primeiro ciclo produtivo.

4. O efeito da adubação nitrogenada na concentração de nitrogênio foi quadrático no primeiro ciclo produtivo e linear positivo no segundo; entretanto, a lâmina de água não exerceu nenhum efeito.

\section{Literatura Citada}

Almeida, F. T.; Bernardo, S.; Marinho, C. S.; Marin, S. L. D.; Sousa, E. F. Teores de nutrientes do mamoeiro 'Improved Sunrise Solo 72/12' sob diferentes lâminas de irrigação, no Norte Fluminense. Revista Brasileira Fruticultura, vol.24, n.2, pp. 547-551, 2002.

Alves, M. da S.; Coelho, E. F.; Paz, V. P. da S.; Andrade Neto, T. M. de. Crescimento e produtividade da bananeira cv. Grande Naine sob diferentes combinações de nitrato de cálcio e uréia. Revista Ceres, v.57, p.125-131, 2010.

Carvalho, A. J. C. de.; Monnerat, P. H..; Martins, D. P..; Bernardo, S.; Silva, J. A. Teores foliares de nutrientes no maracujazeiro amarelo em função de adubação nitrogenada, irrigação e épocas de amostragem. Revista Scientia Agricola, v.59, p.121-127, 2002.

Damatto Júnior, E. R.; Bôas, R. L. V.; Nomura, E. S.; Fuzitani, E.; Garcia, V. A. Alterações nos teores nutricionais foliares de bananeira 'prata-anã' adubada com composto orgânico em cinco ciclos de produção. Revista Brasileira de Fruticultura, v. especial, p 692-698, 2011.

Danilo, E. R.; William N.; Prado, R. de M.; José C. B. Tamanho da amostra foliar para avaliação do estado nutricional de goiabeiras com e sem irrigação. Revista Brasileira de Engenharia Agrícola e Ambiental, v.13, p.233-239, 2009. 
Dantas, B. F.; Pereira, M. S.; Ribeiro, L. de S.; Maia, J. L. T.; Silva, D. J.; Duenhas, L. H.; Lima, M. A. C. de; Bassoi, L. H. Metabolic responses of guava trees irrigated with different $\mathrm{n}$ and k levels in São Francisco Valley. Revista Brasileira de Fruticultura, v.29, p.323-328, 2007.

Embrapa. Centro Nacional de Pesquisa de Solos (Rio de Janeiro, RJ). Sistema brasileiro de classificação de solos. Brasília: Produção de Informação, 1999.

Bassoi, L. H.; Teixiera, A. H. C.; Silva, J. A. M.; Silva, E. E. G.; Ferreira, M. N. L.; Maia, J. L. T.; Targino, E. L. Consumo de água e coeficiente de cultura da goiabeira irrigada por microaspersão. Petrolina, PE Dezembro, 2001 (Comunicado Técnico 112), Petrolina - PE, 2001.

Franco, F. C.; Prado, R. M.; Brachirolli, L. F.; Rozane, D. E. Curva de crescimento e marcha de absorção de macronutrientes em mudas de goiabeira. Revista Brasileira de Ciência do Solo, Viçosa, v. 31, n. 6, p. 1429-1437, 2007.

Gomes, V. M.; Souza, R. M.; Silva, M. M.; Dolinski, C. Caracterização do Estado Nutricional de Goiabeiras em Declínio Parasitadas por Meloidogyne mayaguensis. Revista Nematologia Brasileira, v.32, p.154-160, 2008.

Hoffmann, R. B.; Oliveira, F. H. T. de; Souza, A. P. de; Gheyi, H. R.; Souza Júnior, R. F. de. Acúmulo de matéria seca e de macronutrientes em cultivares de bananeira irrigada. Revista Brasileira de Fruticultura, v.32, p.268-275, 2010.

Lima, J. P. R.; Miranda, E. A. de A. Fruticultura Irrigada no Vale do São Francisco: Incorporação Tecnológica, Competitividade e Sustentabilidade. Revista Econômica do Nordeste, v.32, p.611-632, 2001.

Maia, J. L. T., Bassoi, L. H., Silva, D. J., Lima, M. A. C., Assis, J. S.; Morais, P. L. D. Assessment on nutrient levels in the aerial biomass of irrigated guava in São Francisco Valley, Brazil. Revista Brasileira de Fruticultura, v.29, p.705-709, 2007.

Malavolta, E.; Vitti, G. C.; Oliveira, S. A. Avaliação do estado nutricional das plantas: Princípios e aplicações. 2.ed. Piracicaba: POTAFOS, 1997. 319p.

Melo, A. S. de; Fernandes, P. D.; Sobral, L. F.; Brito, M. E. B.; Dantas, J. D. M. Crescimento, produção de biomassa e eficiência fotossintética da bananeira sob fertirrigação com nitrogênio e potássio. Revista Ciência Agronômica, v.41, p.417-426, 2010.

Mendonça, F. C.; Medeiros, R. D. de; Botrel, T. A.; Frizzone, J. A. Adubação nitrogenada do milho em um sistema de irrigação por aspersão em linha. Scientia Agricola, v.56, p.1035-1044, 1999.
Moura, A. P. de; Moura, D. C. M. de. Levantamento e flutuação populacional de parasitoides de moscas-das-frutas (diptera: tephritidae) de ocorrência em goiabeira (Psidium guajava L.) em fortaleza, Ceará. Arquivos do Instituto Biológico, v.78, p.225-231, 2011.

Natale, W. Coutinho, E. L. M.; Boaretto, A. E.; Pereira, F. M. Goiabeira: calagem e adubação. Jaboticabal: FUNEP, 1996. 22 p.

Oliveira, F. de A. de; Medeiros, J. F. de; Lima, C. J. G. de S.; Dutra, I.; Oliveira, M. K. T. de. Eficiência agronômica da fertirrigação nitrogenada e Potássica na cultura do meloeiro nas condições do semiárido Nordestino. Revista Caatinga, v.21, p.05-11, 2008.

Pereira, F. M.; Nachtigal, J. C. Melhoramento da goiabeira. In: Melhoramento de Fruteiras Tropicais. Viçosa: UFV, 2002. 422p.

Prado, R. de M.; Natale, W. Calagem na nutrição de cálcio e no desenvolvimento do sistema radicular da goiabeira. Pesquisa Agropecuária Brasileira, v.39, p.1007-1012, 2004.

Rozane, D. E.; Brugnara, V.; Souza, H. A.; Amorim, D. A. Condução, arquitetura e poda da goiabeira para mesa e/ou indústria. In: Natale, W.; Rozane, D. E.; Souza, H. A.; Amorim, D. A. Cultura da goiaba do plantio à comercialização. Jaboticabal: FCAV/Capes/CNPq/ FAPESP/Fundunesp/ SBF, v. 2. pp. 429-470, 2009.

Sant'Ana, E. V. P.; Santos, A. B.; Silveira, P. M. Adubação nitrogenada na produtividade, leitura spad e teor de nitrogênio em folhas de feijoeiro. Pesquisa Agropecuária Tropical, v. 40, n. 4, p. 491-496, 2010.

Santos, V. P.; Fernandes, P. D.; Melo, A. S.; Sobral, L. F.; Brito, M. E. B.; Dantas, J. D. M.; Bonfim, L. V. Fertirrigação da bananeira cv. prata-anã com N e K em um argissolo vermelho-amarelo. Revista Brasileira de Fruticultura, Jaboticabal, v.31, n.2, p.567-573, 2009.

Sousa, A. e. C.; Bezerra, F. M. L.; Sousa, C. H. C. de.; Santos, F. S. S. dos. Produtividade do meloeiro sob lâmina de irrigação e adubação potássica. Engenharia Agrícola, Jaboticabal, v.30, p.271-278, 2010.

Sousa, V. F. de; Borges, A. L.; Coelho, E. F.; Vasconcelos, L. F. L.; Veloso, M. E. da C.; Oliveira, A. S. de; Aguiar Netto, A. de O. Irrigação e fertirrigação do maracujazeiro. Teresina: Embrapa Meio-Norte, 2001. 48p. Circular Técnica, 32

Taiz, L.; Zieger, E. Fisiologia vegetal. 3.ed. Porto Alegre: Artmed, 2004. 719p.

Teixeira, L. A. J.; Quaggio, J. A.; Mellis, E. V. Ganhos de eficiência fertilizante em bananeira sob irrigação e fertirrigação. Revista Brasileira de Fruticultura, v.33, p.272-278, 2011.

Vilela, L.; Sousa, D. M. G. de; Silva, J. E. da. Adubação potássica, Cerrado: Correção do solo e adubação. Brasília: Embrapa Informação Tecnológica, 2004. 416p. 